\title{
Divergência genética entre cultivares de feijão comum cultivados no estado do Tocantins
}

\author{
Taynar Coelho de Oliveira Tavares ${ }^{1}$, Sérgio Alves de Sousa ${ }^{1}$, Marilia Barcelos Souza Lopes ${ }^{1}$, \\ Danilo Alves Veloso ${ }^{1}$, Rodrigo Ribeiro Fidelis ${ }^{1}$. \\ ${ }^{1}$ Universidade Federal do Tocantins, Campus Universitário de Gurupi, Gurupi, Tocantins, Brasil. E-mail: taynarcoelho@ hotmail.com \\ sergio.sousa@ifto.edu.br, mariliabarcelosagro@hotmail.com, danilo.veloso@hotmail.com, fidelisrr@uft.edu.br.
}

Recebido: 17/07/2017; Aceito: 23/07/2018

\section{RESUMO}

A escolha e seleção de genitores podem ser auxiliadas por várias análises multivariadas que orientam os melhoristas na tomada de decisão em um programa de melhoramento, dentre elas, podendo destacar as análises de dissimilaridade genética. Diante disso, objetivou-se com este trabalho avaliar a divergência genética de dezenove cultivares de feijão comum cultivado no Estado do Tocantins. O delineamento estatístico adotado foi o de blocos casualizados com quatro repetições. Para identificar a dissimilaridade das cultivares estudada, avaliou-se altura de planta, inserção de primeira vagem, diâmetro de caule, número de vagem por planta, número de grãos por vagem, massa de 100 grãos e produtividade de grãos. Conclui-se que existe variabilidade genética entre as cultivares estudadas; a massa de cem grãos foi à característica que mais contribuiu para a dissimilaridade genética entre os cultivares. A variabilidade genética permitiu a identificação de cultivares divergentes, sugerindo os cruzamentos entre (IAC Boreal x IPR Chopim), (IAC Boreal x IAC Carioca Eté), (IAC Boreal x IPR Saracura), (IAC Boreal x IPR Corujinha), (IAC Boreal x IPR Colibri), (IAC Boreal x IAC Diplomata), (IAC Boreal x IAC Una), (IAC Boreal x IPR Juriti), (IAC Boreal x IAC Centauro) e (IAC Boreal x IAC Galante) visando à produtividade de grãos.

Palavras-chave: Phaseolus vulgaris, dissimilaridade genética, melhoramento.

\section{Genetic divergence of common bean cultivars cultivated in Tocantins state}

\begin{abstract}
The choice and selection of parents can be helped by several multivariate analyzes that guide breeders in decision making in a breeding program, among which may highlight the analysis of genetic dissimilarity. Therefore, the aim of this study was to evaluate the genetic divergence of nineteen common bean cultivars grown in the State of Tocantins. The statistical design was a randomized block with four replications. To identify the dissimilarity of the studied cultivars, we evaluated plant height, first pod insertion, stem diameter, number of pods per plant, number of grains per pod, 100 grains weight and grain productivity. It was concluded that there is genetic variability among the cultivars studied; the 100 grains weight was the characteristic that most contributed for the genetic dissimilarity among the cultivars. The genetic variability allowed the identification of different cultivars, allowing to suggest the crossing between (IAC Boreal x IPR Chopim), (IAC Boreal x IAC Carioca Eté), (IAC Boreal x IPR Saracura), (IAC Boreal x IPR Corujinha), (IAC Boreal x IPR Colibri), (IAC Boreal x IAC Diplomata), (IAC Boreal x IAC Una), (IAC Boreal x IPR Juriti), (IAC Boreal x IAC Centauro) e (IAC Boreal x IAC Galante) cultivars aiming the grain productivity.
\end{abstract}

Key words: Phaseolus vulgaris, genetic dissimilarity, breeding. 


\section{Introdução}

O feijão comum é um dos principais alimentos utilizados na dieta básica da população, principalmente por ser acessível a todos e apresentar elevado valor proteico. O cultivo do feijoeiro ocorre em quase todo o território nacional, em diferentes condições climáticas e nível tecnológico. Segundo Salgado et al. (2011) o Estado do Tocantins apresenta enorme potencial para o cultivo do feijoeiro, porém, o desenvolvimento de programas de melhoramento genético local ainda é bastante escasso.

A escolha e seleção de genitores pode ser auxiliada por várias análises multivariadas que orientam os melhoristas na tomada de decisão em um programa de melhoramento, dentre elas, podendo destacar as análises de dissimilaridade genética. $\mathrm{O}$ estudo da divergência genética é uma das etapas iniciais imprescindíveis em um programa de melhoramento genético, sendo importante para a escolha adequada dos progenitores com variabilidade genética e as possíveis combinações híbridas. Segundo Borém e Miranda (2013) a escolha dos genitores compõe uma das etapas cruciais para o sucesso de um programa de melhoramento.

Diversos são os estudos de dissimilaridade genética envolvendo a cultura do feijão que vem norteando os melhoristas na escolha apropriada dos genitores (Coelho et al. 2007, Cargnelutti Filho et al. 2008, Cargnelutti Filho et al. 2009, Coelho et al. 2010, Cabral et al. 2011, Kloster et al. 2011, Correa \& Gonçalves 2012 e Gonçalves et al. 2014). A variabilidade detectada pela análise de divergência potencializa a obtenção de ganhos genéticos mais promissores e reduz o número de cruzamentos desnecessários (Elias et al. 2007).

A análise de divergência genética pode ser realizada com vários caracteres, dentre as principais estão: altura de planta, número de vagem por planta, número de grãos por vagem, massa de 100 grãos, produtividade de grãos, sendo observado que a massa de 100 grãos é a que mais contribuem para a diferenciação genética em diversos estudos realizados (Coelho et al. 2007, Cabral et al. 2011 e Correa \& Gonçalves 2012). Em virtude disso, objetivou-se com este trabalho avaliar a divergência genética de dezenove cultivares de feijão comum no Estado do Tocantins.

\section{Material e Métodos}

Para o estudo da divergência genética do feijão comum foram utilizados dados de sete caracteres de feijão de experimento conduzido na Universidade Federal do Tocantins, Campus Universitário de Gurupi, localizado a $11^{\circ} 43^{\prime} 45^{\prime \prime}$ de latitude sul e $49^{\circ} 04^{\prime} 07^{\prime \prime}$ longitude oeste, a $280 \mathrm{~m}$ de altitude, em solo Latossolo Vermelho Amarelo Distrófico (Embrapa, 2013). Os dados climatológicos são mosrtados na Figura 1. As dezenove cultivares de feijão comum avaliadas foram IAC Centauro, IAC Galante, IPR Corujinha, IAC Boreal, IAC Diplomata, IAC Una, IPR Gralha, IPR Tiziu, IPR Graúna, IPR Chopim, IAC Carioca Eté, IAC Carioca Tybatã, IPR Saracura, IPR Juriti, IPR Colibri, IPR Eldorado, IPR Siriri, IPR Tangará e IPR 139.

O preparo do solo foi uma aração e duas gradagens, sendo o experimento implantado em julho de 2010. O delineamento estatístico adotado foi o de blocos casualizados com quatro repetições. Cada parcela experimental foi constituída por quatro linhas de 4,0 m de comprimento, espaçadas de $0,45 \mathrm{~cm}$, visando obter estande final de 12 plantas por metro linear. Como área útil foi considerada as duas linhas centrais com 3,0 m de comprimento cada.

A adubação foi feita de acordo a recomendação para a cultura e baseada na análise de solo. O resultado da análise química e física do solo na camada $0-20 \mathrm{~cm}$ antes da instalação do experimento foi: $\mathrm{pH}$ em $\mathrm{CaCl}_{2}=$ 5,1; M.O $(\%)=1,5 ; \mathrm{P}($ Mehlich $)=4,9 \mathrm{mg} \mathrm{dm}^{-3} ; \mathrm{K}=25,5$ $\mathrm{mg} \mathrm{dm}{ }^{-3} ; \mathrm{Ca}+\mathrm{Mg}=1,1 \mathrm{cmol}_{\mathrm{c}} \mathrm{dm}^{-3} ; \mathrm{H}+\mathrm{Al}=1,4 \mathrm{cmol}_{\mathrm{c}}$ $\mathrm{dm}^{-3} ; \mathrm{Al}=0,0 \mathrm{cmol}_{\mathrm{c}} 6 \mathrm{dm}^{-3} ; \mathrm{SB}=1,1 \mathrm{cmol}_{\mathrm{c}} \mathrm{dm}^{-3} ; \mathrm{V}=$ $45,1 \% ; 737,9 \mathrm{~g} \mathrm{~kg}^{-1}$ de areia; $26,1 \mathrm{~g} \mathrm{~kg}^{-1}$ de silte e 236,0 $\mathrm{g} \mathrm{kg}^{-1}$ de argila. Adubação base foi de $120 \mathrm{~kg} \mathrm{ha}^{-1} \mathrm{de}$ $\mathrm{P}_{2} \mathrm{O}_{5}$ e $70 \mathrm{~kg} \mathrm{ha}^{-1}$ de $\mathrm{K}_{2} \mathrm{O}$ e a adubação de cobertura foi $90 \mathrm{~kg} \mathrm{ha}^{-1}$ de N. Os tratos culturais, como controle de pragas e plantas daninhas foram realizados de acordo com a recomendação da cultura. A água foi disponibilizada por irrigação suplementar na entressafra, sempre que necessária ao desenvolvimento das plantas.

Para verificar a divergência genética das cultivares de feijão avaliaram-se cinco plantas por parcela as seguintes características: altura da planta - medindo do colo da planta até o final da haste principal; altura de inserção de primeira vagem - medindo do solo até o ponto de inserção da primeira vagem; diâmetro do caule - medindo-se no colo da planta com paquímetro digital; número de vagens por planta - pela contagem do número total de vagens na planta; número de grãos por vagem - obtido pela contagem total de grãos oriundos da planta e dividindo o resultado pelo número total de vagens; massa de 100 grãos (g) - tomando-se cem grãos da área útil pesando e corrigindo a umidade para 13\%; produtividade de grãos - através da massa de grãos da área útil em kg ha ${ }^{-1}$, com correção para $13 \%$. Os dados foram submetidos à análise individual, com aplicação do teste F. Utilizou-se o teste de agrupamento ScottKnott, ao nível de 5\% de probabilidade. Para o agrupamento das cultivares utilizou-se o método de otimização de Tocher e o método Hierárquico de agrupamento médio entre grupos (UPGMA), utilizandose a distância de Mahalanobis $\left(\mathrm{D}^{2}\right)$. Além de quantificar a contribuição dos caracteres, por meio da metodologia de Singh. As análises foram realizadas com a utilização do aplicativo computacional GENES (Cruz, 2006). 
Dados de temperatura máxima e mínima $\left({ }^{\circ} \mathrm{C}\right)$ e preciptação $(\mathbf{m m})$

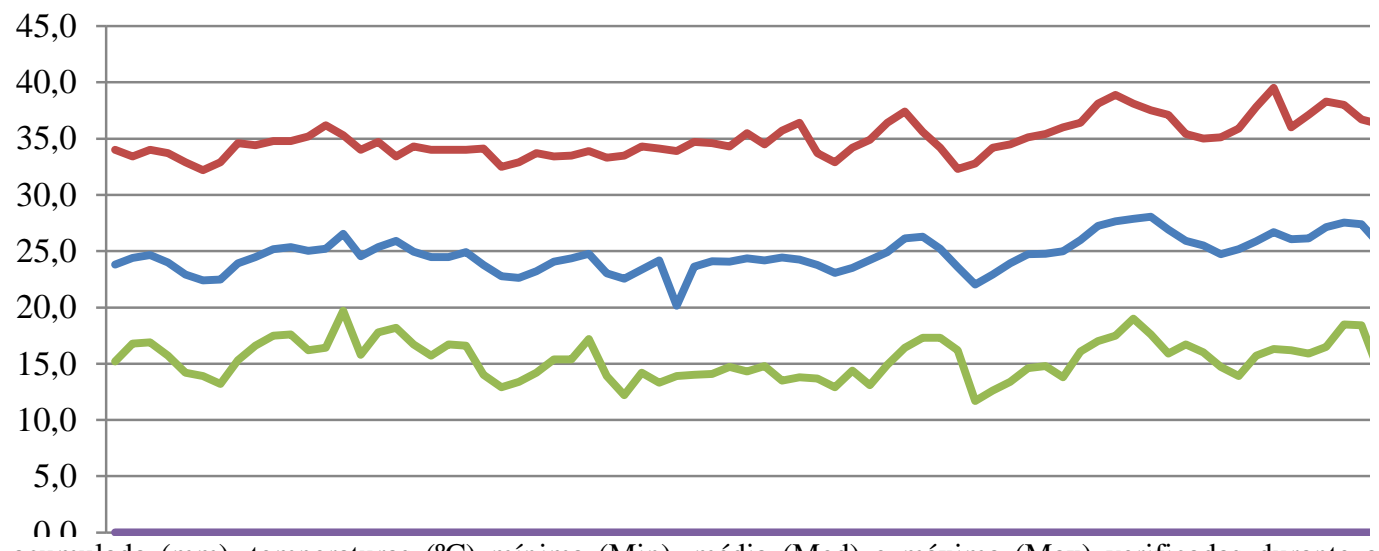

Figura 1. Precipitação acumulada $(\mathrm{mm})$, temperaturas $\left({ }^{\circ} \mathrm{C}\right)$ mínima (Min), média (Med) e máxima (Max) verificadas durante a condução do experimento. (Semeadura: 02/07/2010; Adubação de cobertura: 20 dias após a emergência; Colheita: 23/09 a 02/10/10). (Fonte: Estação Climatológica da Universidade Federal do Tocantins, campus de Gurupi)

\section{Resultados e Discussão}

Observa-se efeito significativo $(\mathrm{p}<0,01)$ entre as cultivares para altura de planta, inserção de primeira vagem, diâmetro do caule, número de vagens por planta, massa de cem grãos e produtividades de grãos (Tabela 1). No entanto, a característica número de grãos por vagem não apresentou diferença significativa. Os coeficientes de variação variaram de 7,48 a $22,22 \%$, indicando adequada precisão experimental para as características avaliadas (Oliveira et al. 2009).

Martins et al. (2002) recomendam cruzamentos de genitores divergentes, mas que apresentem desempenho satisfatório para as principais características agronômicas desejadas.

Com relação ao caráter altura de planta (Tabela 2), verificou-se a composição de três grupos estatístico variando de 75,80 a 41,26 cm. Do grupo com as maiores médias foi composto por cinco cultivares (IPR Chopim, seguido da IAC Carioca Tybatã, IPR 139, IAC Carioca Eté e IPR Tiziu) com médias variando de 75,8 a 64,4 $\mathrm{cm}$. O grupo de médias intermediárias foi constituído por oito cultivares (IPR Saracura, IPR Juriti, IPR Gralha, IAC Diplomata, IPR Tangará, IAC Galante, IPR Corujinha e IPR Graúna) com médias variando de 60,32 a $53,75 \mathrm{~cm}$. O grupo com as menores médias foi formado por seis cultivares (IAC Centauro, IAC Una, IPR Siriri, IAC Boreal, IPR Colibri e IPR Eldorado) com médias variando de 52,12 a $41,2 \mathrm{~cm}$.

Quanto à altura da inserção da primeira vagem, constata-se a formação de dois grupos estatísticos, sendo o de maiores médias constituídos por onze cultivares variando de 25 a $19,9 \mathrm{~cm}$. O grupo com as menores médias foi composto por oito cultivares com médias variando entre 18,75 e $14,10 \mathrm{~cm}$.
Quanto à característica diâmetro do caule, observase a formação de dois grupos estatísticos, sendo que nove cultivares compuseram o grupo com maior média (IPR Chopim, IPR Corujinha, IPR Tangará, IAC Carioca Tybatã, IPR Graúna, IAC Galante, IAC Carioca Eté, IAC Boreal e IPR Juriti), com valores oscilando de 6,42 a $5,72 \mathrm{~mm}$. O grupo com menor média (IPR 139, IPR Tiziu, IAC Una, IPR Siriri, IPR Saracura, IPR Gralha, IAC Diplomata, IPR Eldorado, IAC Centauro e IPR Colibri) com médias variando entre 5,37 a $4,37 \mathrm{~cm}$.

Quanto à característica número de vagem por planta (Tabela 2), observou-se a formação de quatro grupos estatísticos, sendo o de maiores médias composto pelas cultivares IPR-Chopim $(16,80)$ e IPR Corujinha $(15,53)$. Resultado semelhante foi encontrado por Salgado et al. (2011). Enquanto que, o grupo de menores médias foi constituído por oito cultivares IAC Carioca Eté $(8,80)$, IAC Una (8,70), IAC Diplomata $(8,20)$, IPR $139(8,20)$, IPR Tangará $(8,10)$, IAC Centauro $(7,60)$, IAC Galante $(7,60)$ e IAC Boreal $(5,80)$. Quanto ao número grãos por vagem (Tabela 2), não foi detectado diferenças significativas entre as cultivares, apresentando médias de 3,90 a 2,61 grãos por vagem.

Com relação à massa de cem grãos, verifica-se a composição de três grupos, sendo que a IAC Boreal foi aquela que se sobressaiu em relação aos demais. Tal fato pode ser explicado pela característica genética da própria cultivar, apresentando grãos maiores, por isso é enquadrada na classe de sementes especiais. $\mathrm{O}$ segundo grupo foi composto por seis cultivares (IAC Galante, IPR 139, IPR Tangará, IPR Eldorado, IPR Juriti e IPR Siriri) com valores de 28,24 a 24,92 g. Observase que no terceiro grupo a cultivar IAC Carioca Eté teve menor massa de cem grãos com 21,06 g, apesar de não diferir das cultivares com média inferior a 24,42 g. 
Tabela 1. Análise de variância para altura de planta (AP), inserção de primeira vagem (IPV), diâmetro do caule (DC), número de vagens por planta (NVP), número de grãos por vagem (NGV), massa de cem grãos (MCG) e produtividade de grãos (PG) de dezenove cultivares de feijão comum. Gurupi, Tocantins.

\begin{tabular}{|c|c|c|c|c|c|c|c|c|}
\hline \multirow{2}{*}{ F.V. } & \multirow{2}{*}{ GL } & \multicolumn{7}{|c|}{ Quadrado médio } \\
\hline & & $\mathrm{AP}$ & IPV & $\mathrm{DC}$ & NVP & NGV & MCG & PG \\
\hline Cultivares & 18 & $306,81^{* * *}$ & $23,80^{* *}$ & $1,45^{* * *}$ & $29,98^{* * *}$ & $0,56^{\mathrm{ns}}$ & $147,11^{* * *}$ & $224720,40^{* *}$ \\
\hline Blocos & 3 & 94,45 & 10,97 & 0,25 & 7,43 & 0,75 & 0,43 & 267752,02 \\
\hline Resíduo & 54 & 38,51 & 5,19 & 0,52 & 2,42 & 0,46 & 3,61 & 95178,49 \\
\hline Média & & 57,86 & 20,06 & 5,61 & 9,96 & 3,27 & 25,41 & $1.388,24$ \\
\hline CV $(\%)$ & & 10,72 & 11,36 & 12,96 & 15,62 & 20,69 & 7,48 & 22,22 \\
\hline
\end{tabular}

${ }^{\mathrm{ns}}$ não significativo; ${ }^{* * *}$ significativo para $\mathrm{P} \leq 0,01 ;$; Significativo para $\mathrm{P} \leq 0,05$ pelo teste $\mathrm{F}$.

Tabela 2. Médias de altura de planta $(\mathrm{cm})$, inserção de primeira vagem $(\mathrm{cm})$, diâmetro do caule $(\mathrm{mm})$, número de vagem por planta (und), número de grãos por vagem (und), massa de cem grãos (g) e produtividade de grãos $\left(\mathrm{kg} \mathrm{ha}^{-1}\right)$, de dezenove cultivares de feijão comum, Gurupi, Tocantinsl.

\begin{tabular}{llllllll}
\hline Cultivares & AP & IPV & DC & NVP & NGV & MCG & PG \\
\hline 1-IAC Centauro & $52,12 \mathrm{c}$ & $18,20 \mathrm{~b}$ & $4,72 \mathrm{~b}$ & $7,60 \mathrm{~d}$ & $3,50 \mathrm{a}$ & $24,42 \mathrm{c}$ & $1.481 \mathrm{a}$ \\
2- IAC Diplomata & $58,47 \mathrm{~b}$ & $22,80 \mathrm{a}$ & $5,20 \mathrm{~b}$ & $8,20 \mathrm{~d}$ & $3,60 \mathrm{a}$ & $23,61 \mathrm{c}$ & $1.504 \mathrm{a}$ \\
3- IAC Galante & $56,20 \mathrm{~b}$ & $22,93 \mathrm{a}$ & $6,22 \mathrm{a}$ & $7,60 \mathrm{~d}$ & $2,70 \mathrm{a}$ & $28,24 \mathrm{~b}$ & $1.388 \mathrm{a}$ \\
4-IAC Boreal & $49,00 \mathrm{c}$ & $21,00 \mathrm{a}$ & $5,87 \mathrm{a}$ & $5,80 \mathrm{~d}$ & $2,61 \mathrm{a}$ & $49,05 \mathrm{a}$ & $907 \mathrm{~b}$ \\
5-IAC Carioca Eté & $67,52 \mathrm{a}$ & $25,00 \mathrm{a}$ & $5,90 \mathrm{a}$ & $8,80 \mathrm{~d}$ & $3,37 \mathrm{a}$ & $21,06 \mathrm{c}$ & $1.400 \mathrm{a}$ \\
6-IAC Una & $50,30 \mathrm{c}$ & $18,50 \mathrm{~b}$ & $5,37 \mathrm{~b}$ & $8,70 \mathrm{~d}$ & $3,11 \mathrm{a}$ & $23,87 \mathrm{c}$ & $1.861 \mathrm{a}$ \\
7-IAC Carioca Tybatã & $70,85 \mathrm{a}$ & $21,20 \mathrm{a}$ & $6,27 \mathrm{a}$ & $10,07 \mathrm{c}$ & $2,78 \mathrm{a}$ & $23,73 \mathrm{c}$ & $1.103 \mathrm{~b}$ \\
8-IPR Saracura & $60,32 \mathrm{~b}$ & $18,13 \mathrm{~b}$ & $5,37 \mathrm{~b}$ & $9,53 \mathrm{c}$ & $3,72 \mathrm{a}$ & $21,68 \mathrm{c}$ & $1.505 \mathrm{a}$ \\
9-IPR Juriti & $59,67 \mathrm{~b}$ & $16,52 \mathrm{~b}$ & $5,72 \mathrm{a}$ & $11,00 \mathrm{c}$ & $3,90 \mathrm{a}$ & $25,10 \mathrm{~b}$ & $1.586 \mathrm{a}$ \\
10-IPR Colibri & $48,80 \mathrm{c}$ & $21,40 \mathrm{a}$ & $4,37 \mathrm{~b}$ & $9,33 \mathrm{c}$ & $3,33 \mathrm{a}$ & $23,03 \mathrm{c}$ & $1.503 \mathrm{a}$ \\
11-IPR Eldorado & $41,26 \mathrm{c}$ & $14,80 \mathrm{~b}$ & $4,77 \mathrm{~b}$ & $9,26 \mathrm{c}$ & $3,12 \mathrm{a}$ & $26,25 \mathrm{~b}$ & $1.124 \mathrm{~b}$ \\
12-IPR Siriri & $49,50 \mathrm{c}$ & $19,90 \mathrm{a}$ & $5,37 \mathrm{~b}$ & $9,90 \mathrm{c}$ & $3,55 \mathrm{a}$ & $24,92 \mathrm{~b}$ & $1.799 \mathrm{a}$ \\
13-IPR Tangará & $57,70 \mathrm{~b}$ & $21,87 \mathrm{a}$ & $6,40 \mathrm{a}$ & $8,10 \mathrm{~d}$ & $3,07 \mathrm{a}$ & $26,82 \mathrm{~b}$ & $1.149 \mathrm{~b}$ \\
14-IPR 139 & $68,87 \mathrm{a}$ & $20,86 \mathrm{a}$ & $5,52 \mathrm{~b}$ & $8,20 \mathrm{~d}$ & $2,85 \mathrm{a}$ & $27,57 \mathrm{~b}$ & $1.208 \mathrm{~b}$ \\
15-IPR Gralha & $59,35 \mathrm{~b}$ & $18,35 \mathrm{~b}$ & $5,35 \mathrm{~b}$ & $10,87 \mathrm{c}$ & $3,22 \mathrm{a}$ & $23,15 \mathrm{c}$ & $1.293 \mathrm{~b}$ \\
16-IPR Tiziu & $64,40 \mathrm{a}$ & $18,75 \mathrm{~b}$ & $5,52 \mathrm{~b}$ & $10,70 \mathrm{c}$ & $3,08 \mathrm{a}$ & $21,69 \mathrm{c}$ & $1.284 \mathrm{~b}$ \\
17-IPR Graúna & $53,75 \mathrm{~b}$ & $18,60 \mathrm{~b}$ & $5,97 \mathrm{a}$ & $13,40 \mathrm{~b}$ & $3,60 \mathrm{a}$ & $23,87 \mathrm{c}$ & $1.286 \mathrm{~b}$ \\
18-IPR Chopim & $75,80 \mathrm{a}$ & $21,30 \mathrm{a}$ & $6,42 \mathrm{a}$ & $16,80 \mathrm{a}$ & $3,42 \mathrm{a}$ & $22,21 \mathrm{c}$ & $1.432 \mathrm{a}$ \\
19-IPR Corujinha & $55,60 \mathrm{~b}$ & $21,05 \mathrm{a}$ & $6,42 \mathrm{a}$ & $15,53 \mathrm{a}$ & $3,75 \mathrm{a}$ & $22,61 \mathrm{c}$ & $1.554 \mathrm{a}$ \\
\hline Medis Sguida & & &
\end{tabular}

Médias seguidas de mesma letra minúscula na coluna não diferem entre si pelo teste Scott-Knott ao nível de 5\% de probabilidade.

Para a característica de produtividade de grãos, pode-se observar a formação de dois grupos estatísticos (Tabela 2). O grupo com maiores médias foi formando por onze cultivares, sendo que a cultivar IAC Una (1.861 $\mathrm{kg} \mathrm{ha}^{-1}$ ) apresentou a maior produtividade de grãos, apesar de não diferir significativamente dos cultivares com média superior a $1.388 \mathrm{~kg} \mathrm{ha}^{-1}$. Por outro lado, o cultivar IAC Boreal $\left(907 \mathrm{~kg} \mathrm{ha}^{-1}\right)$ foi aquele com menor desempenho produtivo, sem diferir significativamente das cultivares com médias inferiores a $1.293 \mathrm{~kg} \mathrm{ha}^{-1}$.

Com relação às medidas de dissimilaridade genética, estimadas a partir da distância de Mahalanobis (Tabela 3), percebe-se uma elevada variação de 1,70 a 290,72 para as características analisadas, sendo a menor distância observada entre as cultivares IPR Gralha (15) e o IPR Tiziu (16) e a maior distância entre IAC Boreal (4) e IPR Chopim (18), demonstrando assim a presença de variabilidade genética entre os cultivares.

Os dez pares de combinações mais divergentes (Tabela 3), determinadas pela distância generalizada de Mahalanobis ( $\mathrm{D}^{2}$ ii') foram IAC Boreal e IPR Chopim $\left(D^{2}=290,72\right)$, IAC Boreal e IAC Carioca Eté $\left(D^{2}=\right.$ 255,31), IAC Boreal e IPR Saracura $\left(D^{2}=235,96\right)$, IAC Boreal e IPR Corujinha $\left(\mathrm{D}^{2}=234,97\right)$, IAC Boreal e IPR Colibri $\left(D^{2}=209,27\right)$, IAC Boreal e IAC Diplomata $\left(D^{2}=201,58\right)$, IAC Boreal e IAC Una $\left(D^{2}=199,01\right)$, IAC Boreal e IPR Juriti $\left(\mathrm{D}^{2}=186,97\right)$, IAC Boreal e IAC Centauro $\left(\mathrm{D}^{2}=186,53\right)$, e, por fim IAC Boreal e IAC Galante $\left(D^{2}=135,98\right)$. Tal fato demonstra a 
existência da dissimilaridade entres essas cultivares, podendo ser recomendadas para cruzamentos visando à maximização das combinações hibridas de maior efeito heterótico e aumentar a possibilidade de recuperação de genótipos superiores (Cruz et al., 2012).

Os pares de combinações mais similares (Tabela 3), determinado pela distância generalizada de Mahalanobis ( ${ }^{2}$ ii') foram IPR Tiziu e IPR Graúna $\left(D^{2}=1,70\right)$, IPR Saracura e IPR Tiziu $\left(D^{2}=2,52\right)$, IAC Una e IPR Siriri $\left(D^{2}=3,49\right)$, IPR Corujinha e Graúna $\left(D^{2}=3,34\right)$, IAC Carioca Tybatã e IPR Tiziu $\left(\mathrm{D}^{2}=3,36\right)$, e IPR Tangará e IAC Galante $\left(D^{2}=3,73\right)$, IPR Juriti e IPR Gralha $\left(D^{2}=\right.$ 4,36), IAC Diplomata e IPR Colibri $\left(D^{2}=4,57\right)$, IAC Centauro e IPR Siriri $\left(D^{2}=4,89\right)$, IAC Centauro e IAC Diplomata $\left(D^{2}=5,10\right)$, IAC Centauro e IPR Colibrii $\left(D^{2}=5,22\right)$, IPR Colibri e IPR Siriri $\left(D^{2}=5,52\right)$, IAC Centauro e IPR Colibri $\left(\mathrm{D}^{2}=5,70\right)$, IAC Carioca Eté e IAC Diplomata $\left(\mathrm{D}^{2}=5,71\right)$, IAC Centauro e IPR Saracura $\left(D^{2}=6,79\right)$ e, IAC Carioca Tybatã e IPR Saracura $\left(D^{2}=6,83\right)$. Deste modo, essas combinações apresentaram baixa variabilidade genética, não sendo indicadas para utilização em programas de melhoramento genético por hibridação.

A análise de agrupamentos pelo método de otimização de Tocher, possibilitou a formação de dois grupos distintos (Tabela 4). O grupo I foi composto por dezoito cultivares (IPR Gralha, IPR Tiziu, IPR Saracura, IAC Carioca Tybatã, IPR Juriti, IPR 139, IAC Centauro, IAC Diplomata, IPR Tangará, IPR Siriri, IPR Colibri, IAC Carioca Eté, IAC Una, IAC Galante, IPR Eldorado, IPR Graúna, IPR Corujinha e IPR Chopim), correspondendo a $94,73 \%$ das cultivares estudadas. O grupo II foi composto pela cultivar IAC Boreal, demonstrando assim a existência da variabilidade genética entre os cultivares analisados. Para Simon et al. (2012), as análises de agrupamentos tornam-se fundamentais para a escolha dos progenitores, mesmo que sejam conhecidas as distâncias genéticas entre os genitores. A identificação da variabilidade genética dos genitores e as prováveis combinações híbridas de feijão comum foram investidos por Cabral et al. (2011), Correa \& Gonçalves (2012) e Gonçalves et al. (2014).

Tabela 3. Dissimilaridade genética entre dezenove cultivares de feijão comum em relação a sete caracteres, baseado na distância generalizada de Mahalanobis ( $\mathrm{D}^{2}$ ii')

\begin{tabular}{|c|c|c|c|c|c|c|c|c|c|c|c|c|c|c|c|c|c|c|}
\hline C & 2 & 3 & 4 & 5 & 6 & 7 & 8 & 9 & 10 & 11 & 12 & 13 & 14 & 15 & 16 & 17 & 18 & 19 \\
\hline 1 & 5,10 & $\begin{array}{l}11, \\
20\end{array}$ & 186,53 & $\begin{array}{c}18,0 \\
3\end{array}$ & 5,22 & $\begin{array}{c}17,6 \\
8\end{array}$ & 6,79 & 10,63 & 5,70 & 10,70 & 4,86 & $\begin{array}{c}10,3 \\
5\end{array}$ & 10,77 & 9,64 & 13,99 & 24,02 & 61,32 & 37,05 \\
\hline 2 & & $\begin{array}{l}10 . \\
66\end{array}$ & 201,38 & 5.71 & $\underset{3}{12,1}$ & $\underset{3}{12,9}$ & 7.83 & 15,94 & 4,57 & 23,07 & 8,00 & 8.23 & 10,14 & 10,87 & 13,34 & 23,98 & 51,85 & 31,53 \\
\hline 3 & & & 135,98 & $\begin{array}{c}25,0 \\
3\end{array}$ & $\begin{array}{c}12,5 \\
7\end{array}$ & $\begin{array}{c}25,0 \\
6\end{array}$ & $\begin{array}{c}24,0 \\
7\end{array}$ & 22,10 & 15,47 & 19,37 & 8,18 & 3,73 & 14,02 & 23,64 & 31,23 & 31,25 & 75,38 & 41,72 \\
\hline 4 & & & & $\begin{array}{c}255, \\
31\end{array}$ & $\begin{array}{c}199, \\
01\end{array}$ & $\begin{array}{c}224 \\
58\end{array}$ & $\begin{array}{c}235, \\
96\end{array}$ & 186,97 & 209,27 & 161,02 & 176,01 & $\begin{array}{c}152 \\
02\end{array}$ & 164,80 & 218,58 & 249,97 & 207,06 & 290,72 & $\begin{array}{c}234,9 \\
7\end{array}$ \\
\hline 5 & & & & & $\begin{array}{c}26,7 \\
4\end{array}$ & 9,53 & $\underset{3}{10,4}$ & 25,13 & 14,76 & 42,88 & 22,86 & $\underset{5}{17,4}$ & 16,93 & 14,59 & 11,82 & 29,51 & 41,51 & 33,10 \\
\hline 6 & & & & & & $\begin{array}{c}28,1 \\
9\end{array}$ & $\begin{array}{c}14,0 \\
0\end{array}$ & 17,69 & 9,56 & 15,20 & 3,49 & $\underset{1}{17,0}$ & 22,91 & 17,80 & 22,44 & 30,80 & 73,58 & 40,68 \\
\hline 7 & & & & & & & 6,83 & 11,00 & 21,48 & 29,56 & 23,69 & $\begin{array}{c}13,8 \\
8\end{array}$ & 7,62 & 4,99 & 3,36 & 15,80 & 22,53 & 23,48 \\
\hline 8 & & & & & & & & 6,20 & 11,58 & 19,60 & 12,78 & $\begin{array}{c}15,4 \\
9\end{array}$ & 11,68 & 12,74 & 2,52 & 15,68 & 34,08 & 24,55 \\
\hline 9 & & & & & & & & & 19,26 & 12,72 & 12,16 & $\begin{array}{c}13,6 \\
9\end{array}$ & 10,77 & 4,36 & 8,67 & 9,26 & 30,71 & 19,13 \\
\hline 10 & & & & & & & & & & 15,96 & 5,52 & $\begin{array}{c}14,9 \\
2\end{array}$ & 19.61 & 11,59 & 16,32 & 21,45 & 55.92 & 28,13 \\
\hline 11 & & & & & & & & & & & 10,41 & $\begin{array}{c}15,8 \\
6\end{array}$ & 24,15 & 14,27 & 24,15 & 15,71 & 63,39 & 30,05 \\
\hline 12 & & & & & & & & & & & & 9.88 & 18,45 & 13,02 & 20,16 & 18,68 & 59,30 & 25,90 \\
\hline 13 & & & & & & & & & & & & & 9,52 & 13,95 & 20,03 & 18,49 & 54,73 & 28,50 \\
\hline 14 & & & & & & & & & & & & & & 10,75 & 13,07 & 25,57 & 43,76 & 38,86 \\
\hline 15 & & & & & & & & & & & & & & & 1,70 & 7,26 & 23,97 & 15,27 \\
\hline 16 & & & & & & & & & & & & & & & & 13,25 & 22,14 & 20,70 \\
\hline $\begin{array}{l}17 \\
18 \\
\end{array}$ & & & & & & & & & & & & & & & & & 20,16 & $\begin{array}{r}3,34 \\
17,03 \\
\end{array}$ \\
\hline
\end{tabular}

C = Cultivares: 1-IAC Centauro, 2- IAC Diplomata, 3- IAC Galante, 4- IAC Boreal, 5- IAC Carioca Eté, 6- IAC Una, 7- IAC Carioca Tybatã, 8- IPR Saracura, 9- IPR Juriti, 10- IPR Colibri, 11- IPR Eldorado, 12- IPR Siriri,13- IPR Tangará, 14- IPR 139, 15- IPR Gralha, 16-IPR Graúna, 17- IPR Tiziu, 18- IPR Chopim e 19- IPR Corujinha.

Tabela 4. Representação do agrupamento pelo método de otimização de Tocher com base na dissimilaridade entre os 19 genótipos de feijão comum. Gurupi-TO

\begin{tabular}{l|l|l}
\hline Grupo & Cultivares & $\%$ \\
\hline \multirow{3}{*}{ I } & IPR Gralha (15), IPR Tiziu (16), IPR Saracura (8), IAC Carioca Tybatã (7), IPR & \\
& $\begin{array}{l}\text { Juriti (9), IPR 139 (14), IAC Centauro (1), IAC Diplomata (2), IPR Tangará (13), } \\
\text { IPR Siriri (12), IPR Colibri (10), IAC Carioca Eté (5), IAC Una (6), IAC Galante } \\
\text { (3), IPR Eldorado (11), IPR Graúna (17), IPR Corujinha (19) e IPR Chopim (18) }\end{array}$ & \\
\hline II & IAC Boreal (4) & 5,26 \\
\hline
\end{tabular}


Com o método de agrupamento UPGMA foi possível identificar três grupos distintos (Figura 2), onde pode-se visualizar a distância existente entre cada cultivar e cada grupo no Dendograma. O grupo I foi composto por quinze cultivares apresentando similaridade genética, enquanto que, no Grupo III a cultivar IAC Boreal mostrou-se mais divergentes entre as analisadas. Embora os métodos (Tabela 4 e Figura 2) tenham apresentado agrupamento diferente, percebe-se que as cultivares constituintes do grupo I do método Tocher foram enquadrados no grupo I e II pelo método UPGMA, demonstrando que os métodos de agrupamento foram parcialmente similares. Resultados semelhantes foram relatados por Gonçalves et al. (2014) que observaram número de agrupamentos diferentes, porém, não havendo grande discrepância na dissimilaridade dos cultivares.

Evidencia-se na distribuição dos cultivares no dendograma (Figura 2) a baixa dissimilaridade entre 15 cultivares que compõem o grupo I, sendo seis cultivares proveniente do Instituto Agronômica de Campinas e nove do Instituto Agronômico do Paraná, demonstrando que esses materiais apresentam semelhança genética, tendo grãos dos variados tipos comerciais como carioca, preto, mulatinho e rosinha.

A contribuição relativa dos caracteres para a divergência genética dos dezenove cultivares de feijão comum, está exposta na Tabela 5. Observa-se que as características massa de cem grãos, número de vagens por planta e altura de planta contribuíram com 88,23\% da divergência genética entre as cultivares estudadas, que somadas à inserção de primeira vagem, resultaram em maior eficiência na identificação das diferenças entre as cultivares.

No entanto, o diâmetro do caule e número de grãos por vagem foram os caracteres que menos contribuíram para dissimilaridade, correspondendo a 2,72\%. Fato observado por Coelho et al. (2007) que apresentaram a característica de diâmetro de caule com pouca relevância para identificação de divergência genética. Outros resultados foram verificados por (Cabral et al. 2011, Correa \& Gonçalves 2012) que observaram que a produtividade de grãos e número de vagem por plantas não foram às características mais importantes na contribuição para a divergência genética entre os genótipos, embora sejam um dos principais componentes produtivos. Para Coelho et al. (2007) o baixo poder discriminante da produtividade de grãos, pode estar relacionado a baixa diferença produtiva entre os cultivares Desta forma, percebe-se que ao selecionar os genitores divergentes, deve levar em consideração o desempenho dos genitores em relação às principais características de interesse, apresentando índice satisfatório.

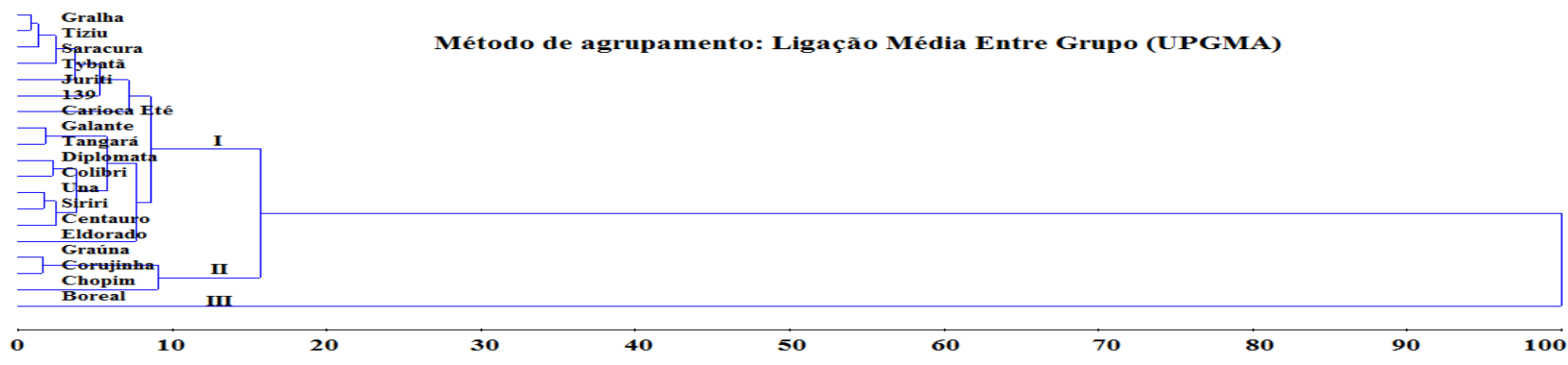

Figura 2. Dendrograma representativo da dissimilaridade genética entre 19 genótipos de feijão, obtidos pelo método de agrupamento UPGMA, utilizando a distância generalizada de Mahalanobis como medida de dissimilaridade (1-IAC Centauro, 2- IAC Diplomata, 3- IAC Galante, 4- IAC Boreal, 5- IAC Carioca Eté, 6- IAC Una, 7- IAC Carioca Tybatã, 8- IPR Saracura, 9- IPR Juriti, 10- IPR Colibri, 11- IPR Eldorado, 12- IPR Siriri,13- IPR Tangará, 14- IPR 139, 15- IPR Gralha, 16-IPR Graúna, 17- IPR Tiziu, 18- IPR Chopim e 19- IPR Corujinha).

Tabela 5. Contribuição relativa dos caracteres para dissimilaridade genética de 19 cultivares de feijão comum de acordo com método proposto por Singh (1981)

\begin{tabular}{ll}
\hline Variáveis & Valor $(\%)$ \\
\hline Massa de cem grãos & 56,11 \\
Número de vagens por planta & 18,67 \\
Altura de planta & 13,45 \\
Inserção de primeira vagem & 5,71 \\
Produtividade de grãos & 3,30 \\
Diâmetro do caule & 2,38 \\
Número de grãos por vagem & 0,34 \\
\hline
\end{tabular}




\section{Conclusões}

Existe variabilidade genética entre as cultivares estudados, sendo possível a identificação das mais promissoras a serem utilizados num programa de melhoramento do feijoeiro comum.

A massa de cem grãos, número de vagem por plantas e altura de planta foram às características que mais contribuíram para a dissimilaridade genética entre as cultivares.

A variabilidade genética permitiu a identificação de cultivares divergentes, sugerindo os cruzamentos entre (IAC Boreal $x$ IPR Chopim), (IAC Boreal $x$ IAC Carioca Eté), (IAC Boreal x IPR Saracura), (IAC Boreal x IPR Corujinha), (IAC Boreal x IPR Colibri), (IAC Boreal x IAC Diplomata), (IAC Boreal x IAC Una), (IAC Boreal x IPR Juriti), (IAC Boreal x IAC Centauro) e (IAC Boreal x IAC Galante) visando à produtividade de grãos.

\section{Referências}

Borem, A., Miranda, G.V., 2013. Melhoramento de plantas, 6 edição. Viçosa: Editora UFV. 523p.

Cabral, P.D.S., Soares, T.C.B., Lima, A.B.P., Alves, D.S., Nunes, J.A., 2011. Diversidade genética de acessos de feijão comum por caracteres agronômicos. Revista Ciência Agronômica, 42, 898-905.

Coelho, C.M.M., Coimbra, J.L.M., Souza, C.A., Bogo, A., Guidolin, A.F., 2007. Diversidade genética em acessos de feijão (Phaseolus vulgaris L.). Ciência Rural, 37, 1241-1247.

Coelho, C.M.M, Zilio, M., Souza, C.A., Guidolin, A.F., Miquelluti, D.J., 2010. Características morfo-agronômicas de cultivares crioulas de feijão comum em dois anos de cultivo. Semina: Ciências Agrárias, 31, 1177-1186.

Correa, A.M., Gonçalves, M.C., 2012. Divergência genética em genótipos de feijão comum cultivados em Mato Grosso do Sul. Revista Ceres, 59, 206-212.
Cruz, C.D., Carneiro, P.C.S., 2006. Modelos biométricos aplicados ao melhoramento genético, 2. ed. Viçosa: Editora $\mathrm{UFV}, 585 \mathrm{p}$

Cruz, C.D., Regazzi, A.J., Carneiro, P.C.S., 2012. Modelos biométricos aplicados ao melhoramento genético, 4. ed. Viçosa: Editora UFV, volume 1, 514p.

Elias, H.T., Vidigal, M.C.G., Gonela, A., Vogt, G.A., 2007. Variabilidade genética em germoplasma tradicional de feijãopreto em Santa Catarina. Pesquisa Agropecuária Brasileira, 42,1443-1449.

Embrapa - Centro Nacional de Pesquisa de Solos., 2013. Sistema brasileiro de classificação de solos, $3^{\mathrm{a}}$ ed. rev. amp. Brasília, DF: Embrapa. 353p.

Cargnelutti Filho, A., Ribeiro, N.D., Reis, R.C.P.dos, Souza, J.R., Jost, E., 2008. Comparação de métodos de agrupamento para o estudo da divergência genética em cultivares de feijão. Ciência Rural, 38, 2138-2145.

Cargnelutti Filho, A., Ribeiro, N.D., Jost, E., 2009. Número necessário de experimentos para a análise de agrupamento de cultivares de feijão. Ciência Rural, 39, 371-378.

Gonçalves, D.L., Ambrozio, V.C., Barello, M.A.A., Neves, L.G., Sobrinho, S.P., Luz, P. B.; Silva, C. R., 2014. Divergência genética de acessos tradicionais de feijoeiros. Bioscience Journal, 30, 1671-1681.

Kloster, G.S., Barelli, M.A.A., Silva, C.R., Neves, L.G., Sobrinho, S.P., Luz, P.B., 2011. Análise da divergência genética através de caracteres morfológicos em cultivares de feijoeiro. Revista Brasileira de Ciências Agrárias, 6, 452-459.

Martins, I.S., Pires, I.E, Oliveira, M.C., 2002. Divergência genética em progênies de uma população de Eucalyptus camaldulenses. Floresta e Ambiente, 9, 81-89.

Oliveira, R.L., Muniz, J.A., Andrade, M.J.B., Reis, R.L., 2009. Precisão experimental em ensaios com a cultura do feijão. Ciência Agrotécnica, 33, 113-119.

Salgado, F.H.M., Fidelis, R.R., Carvalho, G.L., Santos, G.R., Cancellier, E.L., Silva, G.F., 2011. Comportamento de genótipos de feijão, no período da entressafra, no sul do estado de Tocantins. Bioscience Journal, 27, 52-58.

Simon, G.A., Kamada, T., Moiteiro, M., 2012. Divergência genética em milho de primeira e segunda safra. Semina: Ciências Agrárias, 33, 449-458. 